\title{
An Alternative Surgery for an Atypical Kind of Grade C Postoperative Pancreatic Fistula Following Pancreaticoduodenectomy
}

\author{
EDOARDO VIRGILIO, MARCO LA TORRE and MARCO CAVALLINI \\ Medical and Surgical Sciences and Translational Medicine, \\ Faculty of Medicine and Psychology "Sapienza”, St. Andrea Hospital, Rome, Italy
}

\begin{abstract}
Background/Aim: Grade $C$ postoperative pancreatic fistula $(P O P F)$ is a life-threatening complication of pancreaticoduodenectomy (PD), with its surgical management remaining under debate. Occasionally, POPF is associated with a compromised anastomotic Roux-limb. Our series focused to this sort of grade $C$ mixed fistula. Patients and Methods: Between April 2004 and March 2014, 5 out of 12 patients with grade C POPF were classified as grade $C$ mixed POPFs. Surgery consisted of associating resection of the anastomotic jejunal segment with resection and closure of the pancreatic stump. Results: Four patients suffered from a grade $C$ mixed POPF discharging into a single dehiscent site; 1 patient was found with two dehiscent points in all (pancreatic anastomosis and jejunal rim). For all of them, the described surgical procedure resulted in complete recovery. Conclusion: For grade $C$ pancreaticodigestive $P O P F$, resecting anastomotic jejunal segment during dismantling of the pancreatico-digestive anastomosis appears a very promising surgical technique.
\end{abstract}

As of today, the pancreatico-enteric anastomosis (PA) remains the "Achilles heel" of pancreaticoduodenectomy (PD) as it shows the highest rate of dehiscence and related clinical problems (1). Partly due to heterogeneous and confounding previous definitions, but mainly due to the wide spectrum of clinical manifestations that can derive, in 2005, the International Study Group for Pancreatic Fistula (ISGPF)

Correspondence to: Edoardo Virgilio, MD, Ph.D., Medical and Surgical Sciences and Translational Medicine, Faculty of Medicine and Psychology "Sapienza", St. Andrea Hospital, via di Grottarossa 103539, 00189, Rome, Italy. Tel: +39 0633775693, Fax: +39 0633775322 , e-mail: aresedo1992@yahoo.it, edoardo.virgilio@uniroma1.it

Key Words: Pancreaticojejunal fistula, pancreaticodigestive fistula, grade $\mathrm{C}$ pancreatic fistula, POPF, pancreaticoduodenectomy. elucidated postoperative pancreatic fistula (POPF) as a drain output of any measurable volume of fluid on or after postoperative day 3 with an amylase content higher than 3 times the serum amylase activity and categorized it into three grades of clinical severity (2). Most often, POPF runs a benign course resolving spontaneously or with minimallyinvasive procedures (the so-called grade A and B POPFs) (2). On the other hand, in $0.2-$ to $8.9 \%$ of circumstances, it can dramatically go downhill complicating with hemorrhage, pancreatitis, peritonitis or sepsis; such a life-threatening event is known as grade C POPF (2). This sort of fistula is associated with mortality rates of up to $40 \%$ and immediate surgical correction represents the only possible remedy (1$3)$. Of interest, in light of our experience, failure of PA could not be the only anatomophysiologic basis responsible for the development of grade C POPF. Occasionally, in fact, during salvage surgery performed for this type of fistula, we have observed a dehiscent PA associated with a compromised jejunal Rough-limb. In such cases, differently from the traditionally described grade C POPF, we think it should be imperative for surgeons to correct both defects, as restoring the sole PA discontinuity will undoubtedly end up unsuccessful.

\section{Patients and Methods}

Study design. This study was conducted in accordance with the ethical standards laid down in the 1964 Declaration of Helsinki and its later amendments. All participants gave written consent before undergoing surgery. Between April 2004 and March 2014, 12 PD patients experienced a grade $\mathrm{C}$ POPF with hemodynamic instability. All patients were previously admitted at our surgical Department and operated with a Traverso-Longmire procedure (pyloruspreserving PD) for adenocarcinoma of the pancreatic head. All POPFs were diagnosed by measuring the amylase content in the abdominal drainage fluid and clinically assigned to grade $\mathrm{C}$ category according to the acknowledged ISGPF guidelines (2). As treatment, they were all submitted to a re-do surgery, as described in more detail below. 
Surgical technique. The surgical procedure starts with re-laparotomy and abundant lavage of the entire abdominal cavity. Exploration of the pancreatico-digestive and bilioenteric anastomosis, as well as the status of the anastomozed intestinal loop, is mandatory because it permits to exclude the co-existence of hepaticojejunal fistula, observe the integrity of jejunal rim, determine the width of the pancreatic dehiscence, as well as the nature of the discharged material (pancreatic, pancreatico-biliary or bloody), as theoretically shown in the picture by the yellow drops (Figure 1). However, it should be kept in mind that the access to this anastomosis can be difficult since the jejunal loop is relatively fixed due to the end-to-side hepaticojejunostomy. Hemostasis of an overt bleeding and debridement of necrotic tissue should be attempted at this level. The surgical act continues with dismantling of the pancreatico-digestive anastomosis (Figure 2). The pancreas is dissected, detached from the Roux loop and re-resected by a surgical scalpel; the resulting stump is closed with interrupted sutures of $2 / 0$ monofilament non-absorbable polypropylene. The compromised segment of the Roux-limb harboring the original anastomosis is resected using a GIA linear cutting/stapling device (Proximate ${ }^{\circledR}$ Linear Cutters; Ethicon Endo Surgery ${ }^{\mathrm{TM}}$, Inc., Cincinnati, OH, USA); the cut edge of the jejunal loop is oversewn with running sutures of Vicryl 3.0, while the mesenteric defect is closed using a series of interrupted absorbable sutures. The re-do surgery ends by checking the health status of the two stumps, as well as the hemostasis (Figure 3). A flexible silicone and Jackson-Pratt drain, respectively, placed in the proximity of the jejunal and pancreatic stump, are removed in a few days.

\section{Results}

Classic grade C POPF. At re-laparotomy, 7 patients were diagnosed as having a classic grade $\mathrm{C}$ pancreatic fistula and, thereby, treated with abundant intraperitoneal washings and multiple drains (they are excluded from the present series).

Grade $C$ pancreatico-digestive POPF (grade $C$ mixed $P O P F)$. At salvage re-operation, the remaining 5 patients were found to suffer from a mixed pancreatico-jejunal fistula ensuing from a clear insult to the anastomotic Roux-loop; for these patients, we performed a resection of the anastomotic jejunal segment along with resection and closure of the pancreatic stump (see the Patients and Methods section for a more detailed description of the surgical technique). Of note, all the re-do-interventions were made by the same experienced surgeon.

Intraoperative features. Table I summarizes the main intraoperative and short-term features of the examined patients. The mean operative time was 179 minutes (range $=80-280$ ) and the mean intraoperative blood loss was $420 \mathrm{ml}$ (range $=150-950)$. In three patients (Patients 1, 3 and 5) the perianastomotic Roux-limb resulted to be ischemic; hence, the pancreatico-jejunal (PJ) anastomosis was deemed to be dehiscent mostly by the intestinal side. In Patient 2 , the anastomotic Roux-loop was entirely occupied by a wide intraluminal clot resulting from a pancreaticojejumal arterial bleeding. As a consequence, the intestinal limb was congested and determined an ischemic insult to the PJ anastomosis, as well as to the jejunal rim (there were two dehiscences in all). Patient 5 presented with a wide dehiscence on the intestinal side of the PJ anastomosis.

Recovery. Following the intervention, Patients 2, 3, 4 and 5 recovered rapidly from the life-threatening situation induced by their mixed grade C POPF and were discharged from the hospital without abdominal drain within one month. Patient 1 experienced a severe form of acute respiratory failure not responding to corticosteroids and other medical medicaments; of note, he had no previous history of pulmonary disease. He was later submitted to tracheostomy and transferred to intensive care unit. Recovery was slow but successful and he finally was home without any abdominal or tracheostomy tube after 5 months from the re-laparotomy.

Follow-up. Patients 2 and 4 retain a normal life free from disease and are presently on a regular oral diet 6 and 2 years, respectively, after the intervention. At 8-year followup, Patient 1 experienced a pyogenic liver abscess (PLA) due to Escherichia coli necessitating percutaneous drainage and systemic antibiotics. In fact, PLA is an extremely rare and late complication of PD (4). Currently, at 9 years and 4 months of follow-up, he retains a satisfactory health state. Patient 3 and Patient 5 have been conducting a satisfactory life for 2 years and 4 months and 6 months, respectively, before dying of widespread metastatic disease. All living patients are currently under pancreatic enzyme replacement therapy.

\section{Discussion}

The occurrence of grade C POPF represents the most feared complication after PD since it is associated with mortality rates of up to $40 \%$ (1-3). Non-operative management can be initially attempted but, soon, concomitant bleeding, pancreatitis, peritonitis, sepsis, clinical deterioration up to hemodynamic instability affect nearly all patients making redo surgery imperative and the only salvage treatment (1-3, $5-19)$. In this regard, so many surgical alternatives are available today that surgeons are often spoiled for choice; however, it is important to say that no procedure has met with unanimous consensus thus far (1-3, 5-19). Completion pancreatectomy has been long advocated as the operation of choice because it decreases the erosion exerted by pancreatic juice; however, its use has been progressively retrenched because of the demanding accomplishment, significant mortality rate $(38-64 \%)$ and severe related consequences (both exocrine and endocrine pancreatic insufficiency, including a complex diabetic condition named "brittle" diabetes, with a mortality rate of $3.5 \%$ ) (5-7). The 


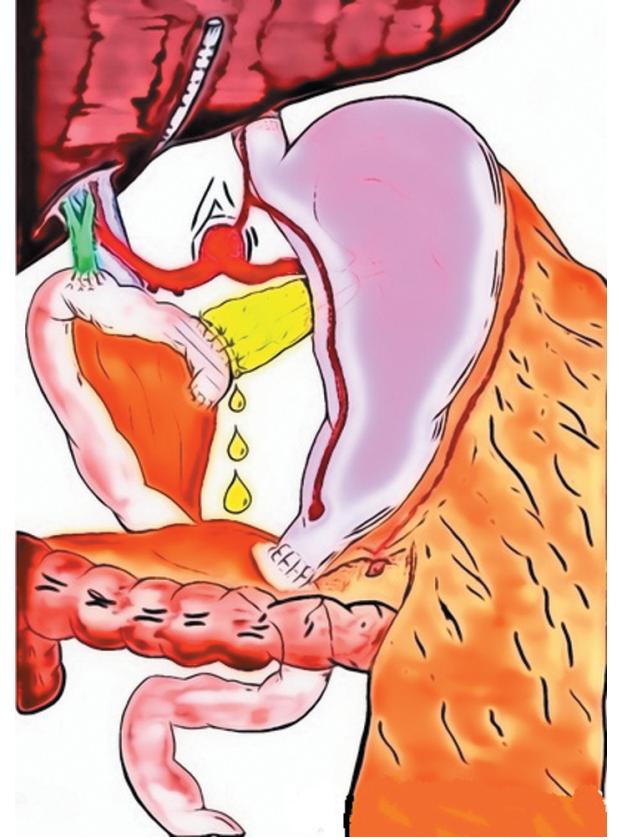

Figure 1. Grade C mixed postoperative pancreatic fistula (POPF) is represented by some yellow drops oozing from the pancreaticodigestive anastomosis. Straight lines of purple dots indicate the compromised segment of the Roux-en-Y jejunal loop due to ischemia, necrosis or congestion. On occasion, concomitant leakage may be also observed flowing from jejunal stump (mixed POPF with two dehiscent points, not shown).

conservative techniques, which preserve the viable pancreatic remnant, such as pancreatogastrostomy, prompt or delayed re-pancreaticojejunostomy, internal or external wirsungostomy, although enthralling and quite successful, appear somewhat venturesome to accomplish as salvage procedures in precipitated situations $(1,3,5,8-10)$. On the other hand, other types of interventions, such as surgical drainage of the anastomotic region or disconnection of the pancreatico-jejunal anastomosis with closure and conservation of the pancreatic stump, although easier to conduct, are associated with a high risk of persistent POPF and elevated mortality rate $(3,5,8,11)$.

As for our ten-year experience, we have observed that grade C POPF may present not only with a classic shape (that is the purely pancreatic leakage) but also, on occasion, in association with a compromised anastomotic jejunal loop causing a concomitant biliary-enteric leakage: we indicated this sort of fistula as grade $\mathrm{C}$ mixed POPF. Paralleling our hypothesis, other authors have formerly noticed the existence of this kind of combined break-down (12-14). Recently, furthermore, Hackert and colleagues vented the need to redefine category $\mathrm{B}$ and $\mathrm{C}$ of POPF after 10 years of the

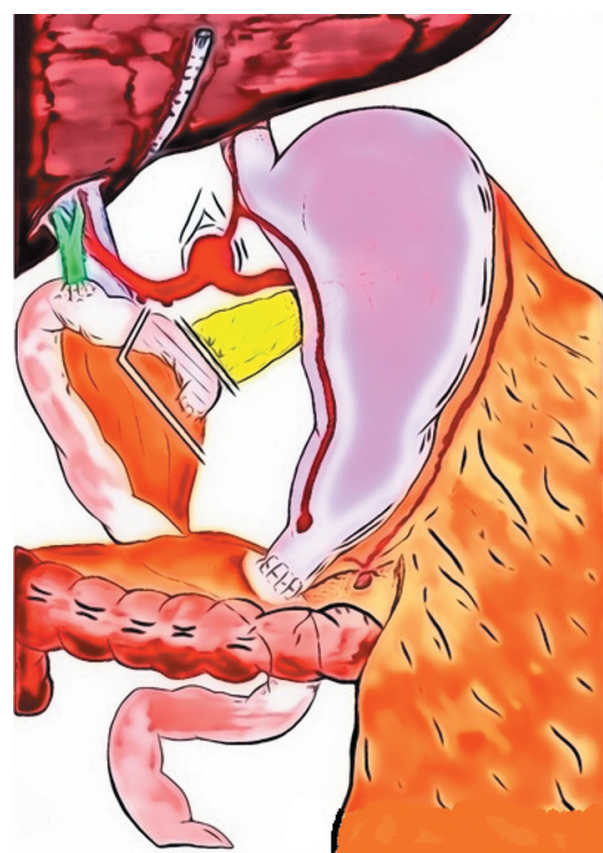

Figure 2. Dismantling of the pancreatico-digestive anastomosis: reresection and closure of the pancreatic remnant coupled with resection of the damaged jejunal portion.

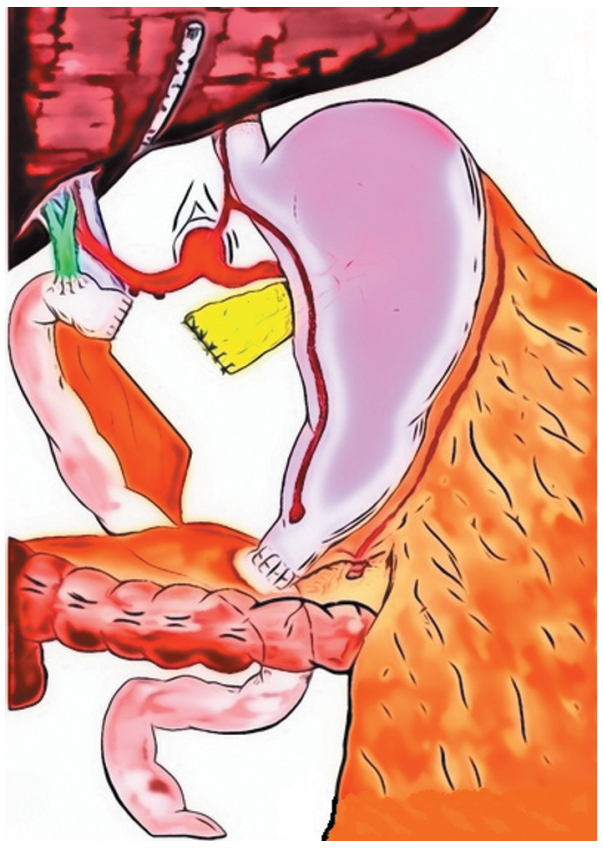

Figure 3. Intraoperative view following salvage intervention. 
Table I. Main perioperative features of patients undergoing intestinal resection for grade C mixed POPF.

\begin{tabular}{|c|c|c|c|c|c|c|c|}
\hline Case & Age & Gender & $\begin{array}{l}\text { Days } \\
\text { from PD }\end{array}$ & $\begin{array}{l}\text { Main problem with the } \\
\text { anastomotic Roux-limb }\end{array}$ & $\begin{array}{l}\text { Operative } \\
\text { time (min) }\end{array}$ & $\begin{array}{l}\mathrm{n}^{\circ} \text { of intraoperative } \\
\text { transfusions }\end{array}$ & $\begin{array}{l}\mathrm{n}^{\circ} \text { of postoperative } \\
\text { transfusions }\end{array}$ \\
\hline 1 & 57 & M & 2 & PII & 280 & 3 & 6 \\
\hline 2 & 67 & $\mathrm{~F}$ & 8 & $\begin{array}{l}\text { Arterial hemorrhage, intraluminal } \\
\text { clot and dehiscent rim }\end{array}$ & 150 & 1 & 0 \\
\hline 3 & 76 & M & 7 & PII & 80 & 1 & 0 \\
\hline 4 & 29 & M & 10 & Wide anastomotic intestinal dehiscence & 255 & 1 & 1 \\
\hline 5 & 72 & M & 7 & PII & 130 & 1 & 0 \\
\hline
\end{tabular}

POPF, Postoperative pancreatic fistula; PD, pancreaticoduodenectomy; PII, perianastomotic intestinal ischemia; M, male; F; female.

ISGPS classification (15). As previously postulated by Cullen and associates, surgery of grade $\mathrm{C}$ mixed fistula should be distinguished from the one applied to traditional grade $\mathrm{C}$ POPF (12). In fact, in this particular setting, "[...] the patient's clinical deterioration is not only caused by the open pancreas resection surface, but rather by intestinal leakage. Considering this knowledge, removal of the pancreas remnant in the context of a grade-C fistula can be considered an unnecessarily highrisk overtreatment" (12). However, although this and other succeeding papers surrounding this particular subject have described a profusion of surgical techniques, so far no one has been mentioning of including intestinal resection to the operative management of pancreatic stump (1-18). Interestingly, this omission seems to be flanked with another important anatomopathologic aspect overlooked by nearly all authors: the condition of the Rough-limb anastomozed to the pancreas. In fact, this jejunal portion has been rarely described in the literature dealing with grade C POPF $(1,11,16,17)$.

However, as seen in our cases, the connected jejunal loop can be compromised by bleeding or ischemia not so infrequently. In this context, the bile can re-flow extraluminally through the pancreatico-digestive anastomosis (resulting in a mixed POPF with a single dehiscent site) or from the rim of the jejunal stump aggravating a pre-existing purely pancreatic fistula (mixed POPF with two different points of dehiscence). In our series, the anastomotic loop of the Roux-en-Y pancreatico-jejunostomy was ischemic in three patients (Patients 1, 3 and 5), occupied by a wide intraluminal clot in one case (Patient 2) and widely dehiscent in Patient 4. In addition, in one case, there was a mixed POPF with two dehiscent sites (Patient 2). As a consequence, for grade $\mathrm{C}$ mixed POPF we are of the opinion that the surgical correction should be tailored to pancreas, as well as jejunum because of the two-fold nature of this type of leakage made of pancreatic juice and intestinal content; an incomplete operation would undoubtedly result unsuccessful. This is the reason why we submitted our five patients to a surgical resection and closure technique of the pancreatic remnant in concert with resection of the damaged jejunal segment. In this manner, in fact, once PA has been dismantled, the closure of the pancreatic stump can heal fistulous and hemorrhagic problems arising from the pancreatic tissue; additionally, the resection of the affected jejunal segment eventually permits the absence of biliary or hemorrhagic discharge from the small bowel. In all cases, this strategy resulted to be successful in the early postoperative course (as salvation procedure from sepsis, bleeding and other life-threatening conditions), as well as in the long-term follow-up, due to the benefits deriving from the pancreas-preserving nature of the adopted intervention. In fact, no patient developed diabetes or malabsorption syndrome.

Our work has certain important limitations. First, it is a case series; further research, including prospective, retrospective and multi-institutional studies, is needed to validate our initial results from generalisations into statistical significance. Second, the small number of patients as a larger population ( $>20$ patients) could statistically strengthen our hypothesis and the related findings. Third, its unicentric nature as a multi-institutional study would definitively provide larger numbers and more reliable conclusions. Given our limited but promising experience with this technique, we encourage its use in the setting of a grade $\mathrm{C}$ pancreaticojejunal POPF in order to disclose its real significance and potential utility.

Our case series suggests that segmental resection of the anastomotic Roux-limb should always be associated with surgical management of pancreatic stump in the setting of grade $\mathrm{C}$ mixed POPF. We think that combination of these two surgical steps might drastically improve the outcome of the patients suffering from this particular type of fistula. More clinical studies are needed in order to corroborate our provisional findings and come to safer conclusions.

\section{Confliwcts of Interest}

The Authors declare no conflict of interest. 


\section{References}

1 Ribero D, Amisano M, Zimmitti G, Giraldi F, Ferrero A and Capussotti L: External tube pancreatostomy reduces the risk of mortality associated with completion pancreatectomy for symptomatic fistulas complicating pancreaticoduodenectomy. J Gastrointest Surg 17: 332-338, 2013.

2 Bassi C, Dervenis C, Butturini G, Fingerhut A, Yeo C, Izbicki J, Neoptolemos J, Sarr M, Traverso W, Buchier M and International Study Group on Pancreatic Fistula Definition: Postoperative pancreatic fistula: An International study group (ISGPF) definition. Surgery 138: 8-13, 2005.

3 Bouras AF, Marin H, Bouzid C, Pruvot FR, Zerbib P and Truant $\mathrm{S}$ : Pancreas-preserving management in reinterventions for severe pancreatic fistula after pancreatectomy: A systematic review. Langenbecks Arch Surg 401: 141-149, 2016.

4 Virgilio E, Mercantini P, Ferri M and Cavallini M: Pyogenic liver abscess: A very late and rare complication after pancreaticoduodenectomy. Microbiol Immunol 60: 568-569, 2016.

5 deCastro SM, Busch OR, van Gulik TM, Obertop H and Gouma DJ: Incidence and management of pancreatic leakage after pancreatoduodenectomy. Br J Surg 92: 1117-1123, 2005.

6 Nentwich MF, El Gammal AT, Lemcke T, Ghadban T, Bellon E, Melling N, Bachmann K, Reeh M, Uzunoglu FG, Izbicki JR and Bockhorn M: Salvage completion pancreatectomies as damage control for post-pancreatic surgery complications: A singlecenter retrospective analysis. World J Surg 39: 1550-1556, 2015.

7 Büchler MW, Wagner M, Schmied BM, Uhl W, Friess H and Z'graggen K: Changes in morbidity after pancreatic resection: Toward the end of completion pancreatectomy. Arch Surg 138: 1310-1314, 2003.

8 Menahem B, Guittet L, Mulliri A, Alves A and Lubrano J: Pancreaticogastrostomy is superior to pancreaticojejunostomy for prevention of pancreatic fistula after pancreaticoduodenectomy: An updated meta-analysis of randomized controlled trials. Ann Surg 261: 882-887, 2015.

9 Horvath P, Beckert S, Nadalin S, Königsrainer A and Königsrainer I: Pancreas-preserving surgical managementof grade-C pancreatic fistulas after pancreatic head resection by external wirsungostomy. Langenbecks Arch Surg 401: 457-462, 2016.

10 Gangi O, Fröschl U, Hofer W, Huber J, Sautner T and Függer $\mathrm{R}$ : Unplanned reoperation and reintervention after pancreatic resections: An analysis of risk factors. World J Surg 35: 230614, 2011.

11 Fuks D, Piessen G, Huet E, Tavernier M, Zerbib P, Michot F, Scotte M, Triboulet JP, Mariette C, Chiche L, Salame E, Segol P, Pruvot FR, Mauvais F, Roman H, Verhaeghe $\mathrm{P}$ and Regimbeau JM: Life-threatening postoperative pancreatic fistula (grade C) after pancreaticoduodenectomy: Incidence, prognosis, and risk factors. Am J Surg 197: 702-709, 2009.
12 Cullen JJ, Sarr MG and Ilstrup DM: Pancreatic anastomotic leak after pancreaticoduodenectomy: Incidence, significance, and management. Am J Surg 168: 295-298, 1994.

13 Paye F, Lupinacci RM, Kraemer A, Lescot T, Chafaï N, Tiret E and Balladur P: Surgical treatment of severe pancreatic fistula after pancreaticoduodenectomy by wirsungostomy and repeat pancreatico-jejunal anastomosis. Am J Surg 206: 194-201, 2013.

14 Pratt W, Maithel SK, Vanounou T, Callery MP and Vollmer CM Jr.: Postoperative pancreatic fistulas are not equivalent after proximal, distal, and central pancreatectomy. J Gastrointest Surg 10: 1264-1279, 2006.

15 Hackert T, Hinz U, Pausch T, Fesenbeck I, Strobel O, Schneider L, Fritz S and Büchler MW: Postoperative pancreatic fistula: We need to redefine grades B and C. Surgery 159: 872-877, 2016.

16 Benzoni E, Zompicchiatti A, Saccomano E, Lorenzin D, Baccarani U, Adani G, Noce L, Uzzau A, Cedolini C, Bresadola $\mathrm{F}$ and Intini $\mathrm{S}$ : Postoperative complications linked to pancreaticoduodenectomy. An analysis of pancreatic stump management. J Gastrointestin Liver Dis 17: 43-47, 2008.

$17 \mathrm{Xu}$ J, Dai X, Bu X, Gao F and Zhang X: Pancreaticojejunal bridge anastomosis: A novel option for surgeon to preserve pancreatic body and tail in urgent reoperation for intraabdominal massive hemorrhage after pancreaticoduodenectomy. World J Surg 34: 2457-2462, 2010.

18 McMillan MT, Vollmer CM Jr., Asbun HJ, Ball CG, Bassi C, Beane JD, Berger AC, Bloomston M, Callery MP, Christein JD, Dixon E, Drebin JA, Castillo CF, Fisher WE, Fong ZV, Haverick E, House MG, Hughes SJ, Kent TS, Kunstman JW, Malleo G, McElhany AL, Salem RR, Soares K, Sprys MH, Valero V 3rd, Watkins AA, Wolfgang CL and Behrman SW: The characterization and prediction of ISGPF grade C fistulas following pancreaticoduodenectomy. J Gastrointest Surg 20: 262-276, 2016.

19 Tol JA, Busch OR, van Delden OM, van Lienden KP, van Gulik TM and Gouma DJ: Shifting role of operative and nonoperative interventions in managing complications after pancreatoduodenectomy: What is the preferred intervention? Surgery 156 : 622-631, 2014.

Received April 17, 2017

Revised April 27, 2017

Accepted May 2, 2017 